Emina Kečo- Isakovićl

UDK: $316.774(497)$

\title{
MEDIJSKA SLIKA I METASLIKA TRANZICIJSKIH DRUŠTAVA NA BALKANU
}

\section{- Sažetak -}

Tematiziraju se sada već svakodnevni komunikacijski problemi u svijetu, njihovo reflektiranje na komunikacijsku zbilju kod nas i u okruženju. Nastoje se bar markirati problemi i ponuditi mogući izlazi iz stanja u kojem mediji jesu. Reflektirajući se na aktualne mislioce s područja komunikacijske znanosti, pokušavamo naznačiti moguće puteve za napuštanje komunikacijskih klopki zasnovanih na upotrebi medija i novoj vrsti ideologizacije medija i upotrebi medija za dalje ideologiziranje društva. Planski se stvara gradnja medija koji ne služe osnovnim medijskim postulatima. Novinarstvo u klasičnoj formi nestaje. Mediji ni za što, mediji koji gube i osnovnu informativnu i edukativnu funkciju, a produkuju niskokvalitetnu zabavu koja planski stvara nizak ukus kod publike medija koji konzumira medije nizašta! Takva publika je idealna za dalje manipulacije u sferi politike. Hljeba i igara, isprobana krilatica davnih vremena, postaje oličenje medijskih produkcija ovdje i u okruženju, na Balkanu.

\section{Ključne riječi: Balkan, Evropa, globalizacija, masmediji, tranzicija, kultura, umjetnost.}

1 Prof. dr. Emina Kečo-Isaković, redovni profesor na Fakultetu političkih nauka Univerziteta u Sarajevu. Doktor filozofskih znanosti. Doktorski seminar u Münchenu, na Institutu za komunikološka istraživanja i Filozofskom fakultetu u Münchenu, pohađala kao stipendist fondacije DAAD. Predaje grupu predmeta iz komunikoloških znanosti i Javno mnijenje. Autor je nekoliko knjiga iz oblasti komunikologije.

Objavila velik broj radova i prijevoda u domaćim i stranim publikacijama. Gostovala na univerzitetima u Beču, Grazu,Voralbergu, Münchenu, Berlinu, Budimpešti, Londonu, Ženevi... i bivšoj Jugoslaviji. Prodekan FPN-a u Sarajevu 2005. - 2008. Osnivač je i rukovodilac prvog postidplomskog studija iz diplomacije na Fakultetu političkih nauka u Sarajevu, 2007. Rukovodilac doktorskih studija iz oblasti komunikologije. Ambasador at large (putujući ambasador) Bosne i Hercegovine pri OSCE-u u Beču i uredu UN-a u Ženevi. 


\section{Uvod}

Koliko je tehnologija unaprijedila komuniciranje, danas već nije tema. Od subatomskog doživljaja do mahalskog, lokalnog, trača informacije dobivamo u momentu izvedbe, događanja. O prednostima koje nam tehnologija nosi sa sobom ne raspravljamo više, samo čekamo nove modele tehničkih aparata komunikacija koje strastveno želimo kao nekadašnje generacije svoje ljubavi. Dobar iPad za susjednim stolom u kavani uzbuđuje više od stvarne LJEPOTICEmodela, za tim istim stolom.

Usmjerenost komunikacijskih suigrača danas je prije svega tehnika.

NISU LI KOMUNIKACIJE U VREMENIMA KADA NISMO ZNALI TAKO DOBRO KOMUNICIRATI BILE ANALITIČNIJE, SERIOZNIJE, KVALITETNIJE?

NISU LI NOVINARSKI URADCI BILI KVALITETNIJI KADA SU SE INFORMACIJE “NJUŠILE” PO KULOARIMA NEGOLI DANAS KADA IH DOBIVAMO NA PLADNJU INTERNETSKIH PORTALA U MOMENTU ZBIVANJA?

DA LI SE PROFESIJA NOVINARA ZAGUBILA U VREMENU I PROSTORU TEHNIČKIH NAPREDAKA?

MCLUHANOVSKO PITANJE TKO ĆE U GLOBALNOM SVIJETU /SELU/ BITI MANIPULATOR PONAVLJAJU GOTOVO SVI MISLIOCI MODERNE, OD GADAMERA DO SLOTERDIJKA, KOJI SE PITAJU O NESTANKU UMJETNOSTI U VREMENIMA NAPRETKA, ALI I BEZNAĐA, VREMENIMA U KOJIMA HUMANIZAM NE STANUJE VIŠE U NAŠIM SUSJEDSTVIMA.

PITANJE KAKVA KORIST OD SVEGA ŠTO GLEDAMO U VREMENU ZBIVANJA JE, GADAMEROVSKI GLEDANO, PITANJE ŠTA TREBA UČINITI S MEDIJIMA I KAKVA ĆE BITI NAŠA ZADAĆA U EVROPI.

Mediji su nam omogućili da uživo gledamo razaranja Vukovara, Dubrovnika, ubijanje Sarajeva, Mostara, novinar Ray Gutmann otkriva konclogore u Trnopolju (čija stratišta i stravične masovne grobnice tek sada obilazi predsjednik Haškog tribunala), a Gutmann je prije 20 godina za svoj novinarski uradak dobio Pulitzerovu nagradu, a nakon toga se ponovo dogodio genocid, u Srebrenici.

NIJE VIŠE FILOZOFSKO PITANJE, NEGO PRAKTIČNO PITANJE: ČEMU MEDIJI U OVOMOSKUDNOM VREMENU?

I DOK SE HÖRDERLIN ČUDIO PJESNICIMA U SVIJETU TEHNOLOGIJE KOJE NEĆE DA RAZUMIJU, MI SMO DANAS U PRILICI DA U NERAZUMLJIVOM SVIJETU MEDIJA PONOVO TRAŽIMO PJESMU I PITAMO SE O BITKU SVOG POSTOJANJA I POSTOJANJA MEDIJA, ADORNOVSKI, NAKON SVEGA!

KADA SMO SVI POSTALI I PRIJENOSNICI I PRIMAOCI INFORMACIJA ISTOVREMENO, A VIŠE NEMAMO U ISPRAŽNJENOM MEDIJSKOM SVIJETU ŠTA REĆI?

A ono što medijski vidimo nećemo da vidimo, jer će vlastiti komoditet doći u pitanje!

ALI NE RADI SE O TOME DA SE NAUČI NEČIM OVLADATI. UPRAVO ĆEMO DRUGOST DRUGOGA U NJEGOVOM BITKU DRUGIM UVIJEK IZNOVA DOŽIVLJAVATI NA SVOJIM VLASTITIM PREDRASUDAMA. TO JE KRAJNJE I NAJVIŠE ČEMU MOŽEMO TEŽITI I ŠTO MOŽEMO POSTIĆI - SUDJELOVATI U DRUGOME, IMATI UDJELA U NJEMU. (Gadamer, Naslijeđe Evrope, str. 26).

Pred izraslim kulturama naroda uvijek tražimo nove nas. Umjesto da uživamo u bogatstvu različitosti i to dograđujemo kao ljepotu i kvalitet života, mi medijski tražimo surogat koji se gleda u cijelom svijetu u varijacijama na 
istu temu - Zvijezda možeš biti ti, ili Farme, Džungle..., koje su sinonimi otuđenosti, izopačenosti, ispražnjenosti duha i afirmacija nove ljudske gluposti kojoj se divimo i doprinosimo trajanju i produžetku gluposti same. UMJETNOST MEDIJA DANAS JE DA UNIŠTI UMJETNOST, DA NE VIDI ONO ŠTO VIDI I DA, NPR., MEDIJSKOM UMJEŠNOŠĆU PONUDI NOVI ZABORAV BITKA U KOJEM NAŠE PAMĆENJE BIVA OPTEREĆENO EVROPSKIM NASLIJEĐEM, U KOJEM JE ŠEKSPIROVA IGRA S LJUDSKOM LOBANJOM SINONIM DANAŠNJIH ŠUTANJA LJUDSKIH LUBANJA PRED KAMERAMA, JUČER U RUANDI I BOSNI, DANAS U SIRIJI I AFGANISTANU, ISILU, PREKJUČE U AUSCHWITZU, MATHAUSENU, JASENOVCU ...!

NAPREDAK EVROPSKE ZNANOSTI JESTE U MEDIJSKOJ MODERNIZACIJI, GLOBALIZACIJI I OTKRIVANJU KULTURA, A NE TVORBI MEDIJSKIH UNIFIKATA. EVROPA KAKVU SANJAMO JE EVROPA RAZUMIJEVANJA I UPOZNAVANJA JEDNIH S DRUGIMA, A NE EVROPA OPETOVANIH MEDIJSKIH SADRŽAJA I SVIJETA NAMETNOG SPEKTAKLA.

HEGEL NAM JE NAJAVIO KRAJ UMJETNOSTI, ALI SU MEDIJI OTVORILI NEKU NOVU VRSTU UMJETNOSTI, POČETAK SPEKTAKLA.

MEDIJ JESTE PORUKA, MCLUHANOVSKI, I SVE JE NAŠ PRODUŽETAK U PROSTORU I VREMENU, U NOVOM KODIFICIRANOM SVIJETU.

UMJESTO DA ISPRAVLJAMO RAZLOGE NASTANKA PICASSOVE GERNIKE, BERBEROVE ILI ZECOVE SREBRENICE, NI MEDIJSKI NISMO UKLONILI LOŠE EVROPSKO NASLIJEĐE.

Zbog toga i nema kraja umjetnosti, jer najavljeni kraj predstavlja uvijek početak nastavka novih izražajnih formi koje se rađaju iz komunikacija s nepoznatim svjetovima kojima nastojimo savladati svijet i pripitomiti ga na novi način, način savremenih medija.

TO NIJE MILTONOV RAJ, naŽalost, TO JE HUXLEYJEV VRLI NOVI SVIJET!

TRANZICIJSKE DRŽAVE NAŠEG OKRUŽENJA USPOSTAVILE SU NEKI NOVI KOMUNIKACIONI KOD, SASVIM SLIČAN, UPRKOS SADA JOŠ VEĆIM RAZLIKAMA MEĐU NAMA.

Generalno, zajednička nam je odrednica da ne samo ne znamo kvalitetno planirati svoju budućnost, komentirati sadašnjost, ne znamo ni čuvati svoje nasljedstvo ostavljeno nam kao kulturno blago koje je danas ugroženo upravo nesposobnosću onih koji upravljaju tim blagom i koji ga ne znaju ni medijski plasirati, a kamoli sami zbrinuti.

MOŽDA ZATO ŠTO KULTURNO BLAGO TRAŽI VELIK ANGAŽMAN, A NE OBEĆAVA VELIK MATERIJALNI PROFIT!

Neodgovarajućim i lošim odnosom prema onom što smo naslijedili i imamo kao kulturno blago ostavlja se još više mjesta mahalskom (palanačkom) duhu. INDUSTRIJA KULTURE NAJNIŽEG RANGA, MANIFESTIRANA U FORMI NOVOG KIČA NOVIH MEDIJA, JOŠ I VIŠE NEGO U VREMENIMA POČETAKA RAZVOJA KULTURNE INDUSTRIJE UNIŠTAVA ONO MALO DUŠE ŠTO JE PREOSTAJALO U SADA VEĆ KLASIČNIM KULTURNIM INDUSTRIJAMA SREDINE PROŠLOG VIJEKA.

PODSJETIMO SE DA JE VELIKI IVO ANDRIĆ, KOJI JE UNIVERZALNA BAŠTINA OVIH PROSTORA DOBIO 1961. GODINE NOBELOVU NAGRADU ZA KOMPLETAN KNJIŽEVNI OPUS O HISTORIJI JEDNOG NARODA, IZGUBIO U RODNOM TRAVNIKU ULICU, KOJU JE IMAO, JER SE NOVIM NACIONALNIM OLIGARSIMA NIJE DOPAO NJEGOV KNJIŽEVNI OPUS I PREDSTAVLJANJE NARODA NIJE BILO U DUHU NJIHOVIH PROMIŠLJANJA NEKE NOVE ESTETIKE NACIONALNIH PRIMITIVIZAMA I PALANAČKO-MAHALSKE VIZIJE BUDUĆNOSTI, A DA NAS NITKO NIJE PITAO O TOME!

Nismo čuli neke medijske opservacije i znanstvene analize o razlozima ovoga čina ili činova, jer to se istovremeno dešavalo u više gradova Bosne i Hercegovine. Neka medijska orkestracija odnekud ipak postoji, ma koliko komuniciranje kod nas na prvi pogled izgleda neorganizirano i stihijsko. ŠTA ĆE NJIMA (NAMA) IVO ANDRIĆ U OVIM OSKUDNIM VRMENIMA KAD NI ON NE DONOSI NEKI MATERIJALNI PROFIT!!! 
Nikoga, a posebno medije, ne brine što tako lahko odbacujemo vrijednosti apsolutno dokazane na svjetskom nivou. Čak ni naši edukatori ne brinu što izgubiše ispred nosa kulturnog džokera za sva vremena. Za ulice i njihove nazive, manje-više - budu i prolaze i vraćaju se, ovisi od vlasti, jer je to na Balkanu svuda veoma moguće. Prisjetimo se uklanjanja i vraćanja ogromnih spomenika u Zagrebu, Beogradu, mijenjanja imena prostora, naših prostora trgova, ulica, mostova...

\section{Tranzicija na Balkanu - politička, kulturna, medijska...}

Medijsku i kulturnu sliku uopće na Balkanu krajem XX stoljeća određuju dvije komponente:

- razdoblje tranzicije

- okolnosti ratnih dešavanja.

Niti jedan od ovih činilaca nije kulturni, ali posljedice po kulturu i razvoj medija su time bitno određeni za period u kojem živimo ovo sada.

Materijalne posljedice ugrožavanja i razaranja kulturnih blaga se ne mogu izbrojati - od razaranja divnog grada Dubrovnika, u kojem se ponovno okupljamo kao oko vatre koja treba da nas grije evropskim ozračjem, do rušenja, na UNESCO-ovoj Listi svjetske baštine - mostova nulte vrijednosti, u Mostaru i drugdje, uništavanja, razaranja bogomolja, paljenja Nacionalne i univerzitetske biblioteke $\mathrm{BiH}$, u kojoj je gorjela historija i države i naroda i u kojoj je pred očima Evrope s knjigama koje su svjedočile o ogromnom kulturnom blagu podneblja spaljena i savjest Evrope.

Da li uistinu i ima te savjesti, nakon svega?

Jer međunarodne trupe, koje su trebale da štite zemlju od razaranja (???), uredno su bilježile u dnevnike svaku ispaljenu granatu, metak, naravno i plamen lomače knjiga Nacionalne biblioteke u Sarajevu, što su također uredno zabilježile sve medijske kuće svijeta. Knjige dobro i dugo gore, dovoljno dugo da mediji sve medijski zabilježe, uglavnom bez komentara.

Mi danas nemamo komentara za ovo samo pitanje: Je li to evropska kultura da lomače knjiga posmatra iz daljine, da bi se kasnije naučili da i lomače ljudi bilježe spokojno i uredno, da se arhivira za historiju koju će izučavati u nekim budućim evropskim institucijama za ljudska prava?

Evropa se uredno iskupljuje, kao poslije svake kataklizme, te sanira ratne štete. U Dubrovniku je sanirano materijalno oštećenje, most u Mostaru ponovno spaja obale i nalazi se u svim evropskim turističkim prospektima, Nacionalna biblioteka, inače Vijećnica Austro-Ugarske Monarhije, ugostila 
je na stotu obljetnicu početka I svjetskog rata brojne svjetske dužnosnike, ali miris paljevina knjiga u Sarajevu, kao nekoć u Berlinu, dugo će ostati u onima koji su ga udisali.

Ali, oni koji su je pohodili svečarski na obljetnicu obilježavanja sarajevskog atentata 1914. godine, koji je potresao i preokrenuo tadašnji (ali i sadašnji) svijet, nisu osjetili tu tegobu. Samo svjetlost i medijska pozornost su dovoljne da se sve ljudske nesreće i zaborave, jer to nije spektakl!

Nematerijalne posljedice uništavanja kulture su dugotrajnije. Raspad vrijednosti, uništavanje profesionalizma, zatvorenost kultura, rezultati rata i tranzicije koriste se za opravdanje i ispriku za naše zidove i zatvorenosti koje se danas ispoljavaju u nerazumijevanju latinice i ćirilice, kojima su ispisane stranice kulture ovih podneblja.

Kulturu je, npr., u Bosni i Hercegovini tek 2006. godine Vijeće ministara (Vlada $\mathrm{BiH}$ ) uvrstilo u strategiju razvoja države. Materijalni i duhovni kolaps kao posljedica svih događanja s kraja XX i početka XXI stoljeća danas se ogleda u potpunom krahu kulture, pa čak i masovne culture, u samoj državi! Obrazovni sistem je također i urušen i podijeljen do te mjere da nam više ni historijska baština nije ista, i nju dijelimo, kao čitav obrazovni sistem koji se urušava i tokom obrazovanja ili neobrazovanja, uz pomoć mas-medija.

Poražavajuće su činjenice o zatvaranju kulturnih institucija u BiH. Zatvoren je Zemaljski muzej, Historijski muzej, Nacionalna i univerzitetska biblioteka je spaljenja. Nacionalna galerija je zatvorena, a po manjim muzejskim zbirkama danas se obavljaju svadbe, prijemi i pijanke umjesto predstavljanja slika, knjiga, muzike...

Daytonskim sporazumom nisu regulirana pravila kulturnih institucija u državi. Odron bosanskohercegovačkog društva se događa rušenjem svih civilizacijskih tekovina koje smo imali i dobili u naslijeđe od naših prethodnih generacija.

Mediji su razoreni i farme postaju naš svijet bez naše želje, ali sa željom urušivača da se u medijima stvori ekstraprofit, koji se u kulturno razorenom društvu događa brže i više nego je to medijskim regulama i dozvoljeno.

Građani Bosne i Hercegovine uvijek su se okupljali na prosvjede prilikom zatvaranja institucija, ali nema nitko u zemlji koga je to zanimalo ili ga zanima. Sedam temeljnih institucija kulture je zatvoreno, a urušavanje medijskih servisa je na djelu uskraćivanjem financiranja, discipliniranjem i ukroćavanjem novinara koji su još preostale "gorapadi”, ali građanima mogućnost nove nade, nade da će ulice Ive Andrića biti ponos zemlje i spas civilizacije koja se protjeruje iz zemlje zbog novih vilajeta, patrijaršija i kotara, 
u kojima su samo vlastiti atari bitni, jer samo na svome se najbolje otima od naroda i povećava bogatstvo oligarha, bez kontrole medijskih djelatnika koje kontroliraju do te mjere da se o javnosti i civilnom društvu evropskog tipa teško može i govoriti.

\section{Virtualna i stvarna džungla kao model življenja}

MATERIJALNA I NEMATERIJALNA KRIZA, U POSTRATNOM PERIODU REFLEKTIRANA U KULTURNIM INSTITUCIJAMA DRŽAVE, OTVORILA JE ZAPRAVO RAZARAJUĆI PROSTOR, A BOGAMI I VRIJEME - SADAŠNJE I BUDUĆE - RAZORNOM DJELOVANJU KIČA, ŠUNDA, FARMİ, KOJE SE REFLEKTIRA NA CIJELO DRUŠTVO U FORMI RED CARPETA JAVNOG I PRIVATNOG ŽIVOTA - TZV. ZVIJEZDÂ, koje su producirane u liku nekog Ekrema, čija popularnost na portalima dostiže klikove mjerljive milionima likova, koje zapravo mogu biti i mjera našeg civilizacijskog kulturnog pada.

Ako se divimo i podržavamo emisije u kojima taj neuki Ekrem seksualno opslužuje starlete i propalice iz susjednih nam država, to bi u medijskom smislu trebalo da predstavlja nadu u zajednički život (sic!, tako tumače novi edukatori!), a u kulturnom smislu zamjenu vrijednosti barbarstva i civilizacije. Tako kič-čovjek postaje simbol naših prostora.

Bosanski kič-čovjek danas je MAHALAC koji se ponosi porijeklom (uglavnom iz sitnih zanatlijskih obitelji čiji članovi imaju neki biznis i ekonomsku neovisnost, voze najbolja kola, najčešće džipove kao simbole moći i nedodirljivosti, telefoniraju sa najboljih mobitela da bi nam pokazali ekonomsku moć, u markiranoj odjeći zauzimaju mjesta u nekim carpetima, portalima lokalnih jet setova...).

Činjenica da u državi ne rade muzeji i galerije ih i ne dodiruje, jer $u$ muzeju se još može organizirati svadba novih bogatuna i današnjih medijskih miljenika, pa je neka, npr., Fata, sinonim Bosanke (danas pretvoren i u druga imena koja su tamo gostovala i odradila svoje farmerske zadatke iz Farme), sinonim današnje Bosanke koja je Zagreb odavno osvojila! Nismo tačno ustanovili kojim znanjima i vještinama! Samo se sluti, naravno, ali medijska slika novog modela Narcisa(e) širi se medijima svakodnevno, bez mogućnosti da je promijenimo pravim kulturnim vrijednostima i edukativnim sredstvima.

Nezaposlenost u BiH je dosegla cifru od 44,4 procenta! Armija nezaposlenih se danas ne obrazuje dalje, nego se uveseljava i sama razveseljava oprobanom parolom - još od vremena pada velikih imperija svijeta - "Hljeba i igara", farmama i džunglama, da konzumenti ne razmišljaju o stravičnim posljedicama i rata i tranzicije, zaduživanjima kod međunarodnih monetarnih organizacija koje nas uvode u nove forme ropstva, u kojima obrazovana populacija i nije neka prednost, nego, dapače, opasnost da analizira i kritizira i nešto mijenja. 
Vlastodršci - oligarsi - nikada nisu željeli promjene, ni u historiji ni danas. Može li nam to biti utjeha?

Obrazovanje i evropski standardi su udaljeniji nego ikad, a korupcija i političke afere postaju jedine teme u medijima, uz FARME, KOJE NAS SVE UNIZUJU I PRETVARAJU U POTENCIJALNE FARMERE, gdje popularnost izvjesnog Ekrema s pet minuta škole postaje ideal mladih koji mediji afirmiraju prihvatanjem nekritičkog odnosa prema kulturnim nevrijednostima. Ako nešto ne promijenimo u okruženju, geografskom i medijskom, Ekrem će biti edukativni odraz Bosne, pa će, umjesto nobelovaca Andrića i Preloga, ulice po našim kasabama dobivati ekremi i hane, koji postaju edukativni idoli nove Bosne i novog medijskog Balkana, koji se nastalom pinkizacijom šire na našim prostorima.

Mediokritetstvo i ispražnjenost i ideja i ideala rezultiraju poražavajućim stanjemu balkanskojjavnosti, u kojoj se emancipatorska uloga habermasovskih vidika čak ni ne nazire.

Umjesto IZRAVNE emancipacije društva, masmediji postaju promotori dekadencije društva. Te lažne elite koje mediji promoviraju postaju promotori lažnih društava.To kontinuirano prihvatanje lažnog svijeta donosi nam Narcisovu ulogu polusvijesti u kojoj se počinjemo i sami ogledati u takvim medijima kakvi jesu, kao Narcis po vodama i barama u kojima se danima gledao. Gubimo svoje lice.

Mcluhanovski, mi smo se produžili u naše medije i prihvatili ih $u$ sopstveni sistem. Žrtva, konzument medija, postaje vremenom imuna na iritirajuće sadržaje farmi i pinkizacija postaje naša svakodnevica, umjesto Habermasove emancipacije. Mediji su promotori materijalizma u stvaranju savršenih potrošača a zaboravljaju svoju osnovnu funkciju informiranja javnosti. Edukacije javnosti u habermasovskom smislu riječi, u emancipiranju savremenog čovjeka znanjem i otvaranjem vidika, a ne zatvaranjem u primitivizme sopstvenih izgrađenih idola na ogriscima mogućih svjetskih ideala, kao njihova loša i primitivna kopija.

Današnja elita na Balkanu sluša turbo-folk, slika se sa Severinom, Cecom ili Halidom, Karleušom ili Lukasom, učestvuje u kreiranju zvijezda (!!!) koje treba da liče na prethodne zvijezde, da pjevaju baš i njihove turbo-folk pjesme da bi bile medijski lansirane za nove profite i nove celebrityje u već zadanoj formi.

\section{Otvorena društva za otvorene medije}

Kada je Albert Camus izrekao: Bez kulture i relativne slobode koju ona donosi društvo bi bilo samo džungla nije ni slutio da će nova kultura, 
tranzicijska kultura na balkanskim prostorima, donijeti i nove, ovog puta medijske, džungle!

Istina je da umjetnost (kvalitet!) ne može biti monolog. Ali, ako se prisjetimo da Svaki zid znači vrata (Emerson), ponovno prizivamo Camusa da izađemo iz sadašnjih komunikacijskih apsurda.

Ne tražimo vrata ni izlaz drugdje, nego u zidu pored kojeg živimo. Tražimo, naprotiv, odmor, ma gdje se nađe, hoću reći usred same bitke, jer on se tamo i nalazi. Kaže se da velike ideje dolaze na svijet na nogama golubice. Kada bismo pažljivo slušali, možda bismo čak čuli usred graje carstva i nacija, neki laki lepet krila, blagi šum života i nade.

Jedni će reći da nadu donosi narod, drugi-jedan čovjek. Ja mislim da je ona izazvana, oživljena, podržavana od milijuna osamljenika, čija djela $i$ pothvati svaki dan poriču granice i najsurovije prividnosti povijesti da bi na tren zablistala ugrožena istina koju iz svojih patnji i radosti svatko diže za sve. (A. Camus, Govori u Švedskoj, Zagreb, 1976, str. 189).

Možda zato naše razmjene mišljenja i iskustava mogu biti bar naša nada da vjerujemo da svijet i mediji kojima se komunicira danas mogu biti bolji, ne džungla, nego mirno plavo more sa blagim talasima i osunčanim žalom koje nas grije dok mi idemo u svijet bez džungli i farmi, u svijet razmjene informacija i znanstvenih i zabavnih i informativnih i edukativnih sadržaja koji nas obogaćuju i daju nadu da će komunikacija biti više od tržišne džungle i da će humanizacija društava biti ponovna medijska emancipacija, afirmacija kvaliteta i vrijednosti koje sada samo priželjkujemo, dok zatvaramo muzeje i dok se mediji nalaze u borbi za puko preživljavanje koje je moguće samo na farmama.

КАКо, u vremenima kada svaki dan doma ili u susjedstvu neki od vlastodržaca naših društava, država i naših života u vremenima općeg bezvlašća i okupiranih medija -prodatih tajkunima ili često ministrima, gospodarima novih medija i novih demokracija ili starih laži - drži i prostor i naše vrijeme u svojim rukama, sve dok ne završi u zatvoru, uglavnom.

KADA se može desiti emancipacija medija kao preduvjet emancipacije društva? Onda kada mediji ne budu znanje stavljali u posljednje rubrike novinskih izdanja, a emisije iz znanosti i kulture emitirali samo u sitne sate, kada populacija pretežno usni. Kada se svi zajedno razbudimo iz medijskih pećina u kojima jesmo zarad njihovih profita.

Kada svi zajedno odbijemo sadržaje farmi i ne učestvujemo u realizaciji takvog medijskog pomirenja, kada počnemo razmjenjivati originalne sadržaje kultura, domete saznanja, kada tehnologija bude sredstvo, ali ne i jedini razlog postojanja. 
U toj nadi završavam ovo promišljanje sa željom da i sami istrajemo pronalazeći vrata iz zidova u kojima sada svi jesmo zatvoreni u omeđene medijske zidove, bez vlastitih krivnji!

Komunikacija među nama samima i izlaz iz zatvorenih sredina ka evropskim vrijednostima mogu biti put ka savremenim otvorenim društvima, otvorenim za vrijednosti koje su dometi civilizacije. Komunikacije kakve nam sada nude tzv. balkanski mediji, koji nastoje da osvoje, okupiraju, balkanski medijski prostor, sigurno nemaju cilj da ponude emancipaciju - istinsku edukaciju, nego da stvore profit radi kojeg nam nude iskrivljene slike nas samih i stvaraju nove ikone balkanskog primitivizma kojih bi se mitski Narcis stidio. Kada se školarci počnu diviti osvajačima medalja na olimpijadama znanja iz fizike ili matematike, kojima obično ni ime ne znamo, a medijski ekremi budu dio njihovih, ali ne i naših života.

Vijest o promocijama doktora znanosti je na marginama posljednjih stranica u medijima, ali su zato rezultati opstanka na farmi genijalnih farmera u naslovnicama novina i portala i elektronskih medija.

$\mathrm{Na}$ FARMAMA treba ipak da žive životinje, a u medijima znanje i kultura, koji možda donose manje novca, ali zasigurno donose više BOLJE budućnosti.

Mediji sami po sebi nisu ni dobri ni loši, jer ipak oni ovise o nama, hoćemo li ih prihvatiti ili tražiti nove sadržaje, nove puteve, to je pravo koje je naše pravo izbora i naše ljudsko pravo!

Ako prihvatimo sada (iz)nuđene sadržaje pjevaljki, krunisanih i nekrunisanih kraljica kiča, ako odgajamo generacije da postanu kopije tih modnih i muzičkih ikona (ZMBT!), na olimpijadu znanja nećemo nikada stići, nećemo i dalje znati ni imena pobjednika u znanju, nećemo čak dosegnuti ni dostignuća globalizacije, ostat ćemo samo balkansko medijsko selo. McLuhana nećemo više moći ni prizivati, a Habermasova emancipacija će nas definitivno zaobići, kao nekoć Hegelov apsolutni duh.

Konstantinovički rečeno - kriza je velika i naše šanse su velike. Pobijediti pinkizaciju sigurno nećemo uskoro moći, ali ugasiti TV i ne odgajati generacije na farmama balkanske medijazacije, sigurno još možemo. Za početak vlastite emancipacije koja može biti početak opće emancipacije Balkana.

Možda samo treba da se počnemo sami pitati kuda nas vode mediji u datim društvima. Stari Grci su odgovore znali prije nego li je pitanje postajalo glasno. A nismo li mi zaboravili postaviti pitanje? Čemu mediji ako im je cilj da nas utjeraju u sheme balkanskih farmi? Oskudno vrijeme traži bogate i sadržajne medije koji će nam biti izlaz iz velike krize. Možda je došlo vrijeme za medijsku edukaciju i pobunu protiv medija koji nam uništavaju edukaciju i kulturu? 
AKO VEĆ NOVIM GENERACIJAMA NE MOŽEMO OSTAVITI PAMĆENJA U MUZEJIMA, JER NAM NE DAJU DA IH IMAMO, POKUŠAJMO U MEDIJIMA, KOJE MOŽDA JOŠ IMAMO, napraviti iskorak u edukaciji za budućnost, koje se nećemo stidjeti, u kojoj tradicija jest samo dio modernizacije, gdje kvalitet informacije jest znanje primjereno 21. stoljeću, jer mediji dijelom, još uvijek, zavise od nas samih.

To nisu mašine za stvaranje profita, to su sredstva za stvaranje boljeg i svrsishodnijeg svijeta u kojem treba da profiliramo znanja koja nas vode $u$ bolji, komunikativniji svijet, gdje globalizacija daje svima jednake šanse za napredak i upotrebu novih saznanja, novih kodova života u kojima globalizacija nije kontaminacija medijskog prostora, nego emancipacija tog prostora i nas samih.

Vrijeme je da naše pitanje postane glasno.

\section{Zaključna razmatranja}

Vrijeme je i za stvaranje pretpostavki za razvoj demokratskih društava, društava dijaloga, razmjene znanja, iskustava, analiza i pozitivnih i negativnih efekata medija u društvu. Mediji bi trebali da nam se približe i ponovo otkriju kulturu dijaloga, da budu istraživači društva, ne da ga kritiziraju, nego da ga mijenjaju. Mediji kojima je jedina zadaća da nam otkrivaju i nameću zvijezde i zvjezdice, koji nam život unižavaju na stupanj jeftinog preživljavanja i neduhovne egzistencije, pinkizirani mediji, sigurno nisu garant razvoja društva koje želi stići u civilizirani razvijeni svijet - pretpostavkē za razvoj analitičkih i kritičkih medija, medija koji nas educiraju za prihvatanje pravila civilnih društava i za razvoj takvih društava.Tek tad, moći ćemo shvatiti da je spektakl moguć samo u zabavi, a da društveni razvoj predviđa edukaciju koja se očekuje od sredstava masovnih komunikacija. Sama sredstva, dakle, sama po sebi, nisu ni dobra ni loša. Mi im moramo dati svrhu i razlog postojanja koji nije samo ekonomske prirode.

U protivnom, nastavak gradnje ovakvih medija - medija nizašta, skupo će nas stajati. Vrijeme je da medije čitamo na drugačiji način i da ih učinimo drugačijim, razumjeti problem je možda već mogućnost da mijenjamo sistematično izvođenje ovog nesistematičnog pristupa medijima. Oholost bi bila to ne razumjeti i ne činiti ništa da se društvo medijima promijeni.

Društvo ne može, naravno, postati umjetničko djelo preko noći (Marcuse), ali mi možemo nastojati da mijenjamo društvo i da idemo ka tom idealu educirajući se uz medije i educirajući medije same. Tehnička reprodukcija traži društvenu reprodukciju. Društvena reprodukcija očekuje umjetničku 
reprodukciju. Benjaminovski rečeno - Mediji očekuju dušu. Na nama je, još uvijek, da im je udahnemo.

Tiranija gledanja televizije još uvijek nije znak da vidimo. Adornovsko pitanje Čemu još filozofija, kada se nema šta reći moglo bi se transformirati u Čemu mediji ako nemaju šta reći - ako su samo oko, produžetak gledanja vidljivog svijeta oko nas.

Ali oko - produžetak nas u vizuelnim medijima treba gehlenovsku dušu da bi mediji imali svrhu postojanja. Svi mogu gledati, a rijetki vidjeti svijet oko sebe. A uvidjeti, analizirati, educirati i naučiti i druge da vide - trebalo bi biti zadatak medija u budućnosti.

Mediji još uvijek mogu pomoći da učinimo svijet prisnijim.

\title{
MEDIA DEPICTION AND META PICTURE OF TRANSITIONAL SOCIETIES ON THE BALKANS
}

\begin{abstract}
- Abstract -
Here we address the everyday communication problems in the world and how they reflect on communication reality in the country and the region. Our intention is to mark the problems and to offer possible exits from the media landscape as it is today. Through reflections on contemporary thinkers from the field of communication science we will try to indicate possible ways to escape communication traps based on media usage and new sort of ideologisation of media as well as use of media for further ideologisation of the society. There is a construction plan for media which would not serve the basic media postulates. Journalism in its classic form vanishes. Media goodfor-nothing, media that has lost its basic informative and educative function, and produces entertainment of inferior quality which systematically causes a deterioration of taste of the audience consuming media good-for-nothing! Such an audience is ideal for further manipulation in the domain of politics. Bread and circuses, an often verified idiom, becomes the reflection of media production here, in the region, on Balkans.
\end{abstract}

Keywords: Balkan, Europe, globalisation, mass-media, transition, culture, art. 


\section{Literatura}

- $\quad$ Disorder and Order: http:academic. evergreen edu. (January 2013)

- $\quad$ Bodriar, Ž. (1991): Simulakrum i simulacija, Novi Sad.

- $\quad$ Camus, A. (1975): Izabrana djela, Zagreb.

- Giddens, A. (2005): Odbjegli svijet, Zagreb.

- $\quad$ Gadamer (1997): Naslijeđe Evrope, Zagreb.

- Gehlen, A. (1967): Die Seele in Technischer Zeitalter, Hamburg.

- Klosovska, A. (2005): Sociologija kulture, Beograd.

- Langenbucher (2000): Elektronische Medien, Geselschaft und Demokratie, Braunmüllerverlag.

- $\quad$ Sloterdijk, P. (2001): U istom čamcu, Beograd.

- Flusser, W. (2012): To see Onself Die, Berlin. 